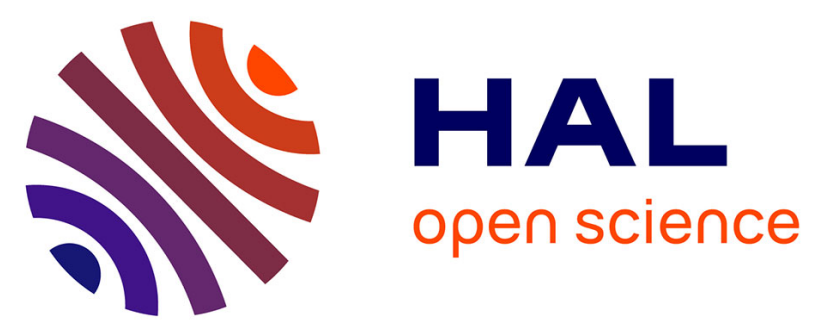

\title{
Effects of music intervention on anxiety and pain reduction in ambulatory maxillofacial and otorhinolaryngology surgery: a descriptive survey of 27 cases
}

Chafik Keilani, Nicolas Simondet, Ramzi Maalouf, Ahmet Yigitoglu, Alexandre Bougrine, Didier Simon, Isabelle Fligny

\section{To cite this version:}

Chafik Keilani, Nicolas Simondet, Ramzi Maalouf, Ahmet Yigitoglu, Alexandre Bougrine, et al.. Effects of music intervention on anxiety and pain reduction in ambulatory maxillofacial and otorhinolaryngology surgery: a descriptive survey of 27 cases. Oral and Maxillofacial Surgery, 2017, 10.1007/s10006-017-0616-3 . hal-01514944

\section{HAL Id: hal-01514944 \\ https://hal.sorbonne-universite.fr/hal-01514944}

Submitted on 26 Apr 2017

HAL is a multi-disciplinary open access archive for the deposit and dissemination of scientific research documents, whether they are published or not. The documents may come from teaching and research institutions in France or abroad, or from public or private research centers.
L'archive ouverte pluridisciplinaire HAL, est destinée au dépôt et à la diffusion de documents scientifiques de niveau recherche, publiés ou non, émanant des établissements d'enseignement et de recherche français ou étrangers, des laboratoires publics ou privés. 


\section{EFFECTS OF MUSIC INTERVENTION ON ANXIETY- AND PAINREDUCTION IN}

AMBULATORY MAXILLOFACIAL AND OTORHINOLARYNGOLOGY SURGERY:

\section{A DESCRIPTIVE SURVEY OF 27 CASES}

Chafik KEILANI (1, 2), Nicolas SIMONDET (1, 3), Ramzi MAALOUF (1), Ahmet YIGITOGLU (1), Alexandre BOUGRINE (1), Didier SIMON (1), Isabelle FLIGNY (1)

(1) Department of otorhinolaryngology and maxillofacial surgery, hôpital Poissy/Saint Germain-en-Laye.

Address : 20 Rue Armagis, 78100 Saint-Germain-en-Laye, FRANCE.

Tel : +33139274000

Fax : +33139274348

Mail : chafik.keilani@gmail.com; chafik.keilani@aphp.fr; chafik.keilani@etu.upmc.fr

(2) Faculty of medicine Pierre et Marie Curie (Paris VI).

(3) Faculty of medicine Paris-lle-de-France-Ouest. 


\section{ABSTRACT}

PURPOSE. The aim of this study is to determine patients' opinion regarding listening to music before an ambulatory maxillofacial surgery and effects on anxiety and pain reduction.

METHODS. This study was conducted on outpatients having a maxillofacial surgery between December 2015 and April 2016 at Poissy/Saint-Germain-en-Laye hospital (France). Patients listened with headphones to an easy-listening music in the operation theatre before the first ambulation. A questionnaire including a Visual Analog Scale (VAS) for pain and anxiety was given to participants. The primary endpoint was to determine patients' opinion regarding listening to music before surgery. Secondary endpoints were to determine VAS pain mean, VAS anxiety mean before surgery, VAS anxiety mean after surgery and if patients wanted to listen to their own playlist. We decided to compare VAS anxiety and pain mean between patients who Accepted to Listen to Music (ALM) and who Refused to Listen to Music (RLM).

RESULTS. 19 patients ALM and 8 patients RLM to music. 78,9\% of patients considered that listening to music before surgery decreased their anxiety. In patients who ALM, the mean (Standard Deviation, SD) of VAS pain after surgery was $3,42(1,95)$, the mean (SD) of VAS anxiety before surgery was $3,1(2,3)$, the mean (SD) of VAS anxiety $1,21(0,85)$. There was a statistically significantly difference of the VAS anxiety mean (SD) before surgery between patients who $\operatorname{ALM} 3,10(2,30)$ and who $\operatorname{RLM~6,12}(1,88)(p=0,005)$. There was a statistically significantly difference of the VAS anxiety mean (SD) after surgery between patients who ALM 1,21 $(0,85)$ and who RLM 2,62 (1,30) $(p=0,009) .50 \%$ of the patients wanted to choose their own music.

CONCLUSION. Music seems to reduce anxiety before maxillofacial surgery. An interventional randomized study is needed to demonstrate the positive impact of music on anxiety before maxillofacial surgery.

Key-words: Maxillofacial surgery; Otorhinolaryngology surgery; Ambulatory Surgery; Pain; Anxiety; Music. 


\section{INTRODUCTION}

Most research regarding anxiety and pain management after maxillofacial and OtoRhinoLaryngology (ORL) surgery has focused on the effect of local and general anesthesia and anxiolytics delivered orally or intravenously [1, 2]. Pain and anxiety are linked. Pain causes stress that leads the cardiovascular system to respond by activating the sympathetic nervous system, resulting in increased heart rate, blood pressure, and oxygen demand. These mechanisms can complicate the quality of a local or general anesthesia during surgery. Furthermore, opioids have sometimes negative side effects such as respiratory depression, vomiting, constipation... One promising but insufficiently understood nonpharmacologic approach to pain and anxiety after maxillofacial and ORL surgery is music therapy. Music has been associated with lower anxiety levels, reduction in analgesic requirements, reduction in anesthetic drugs and shorter procedure times during gastrointestinal procedures and hip surgery [3, 4]. A 2011 randomized controlled study on music for surgical abortion care noted a trend toward a faster decline in anxiety post procedure in music group $(p=0.065)$ [5]. A 2008 and 2015 systematic review of randomized controlled trials of the effects of music interventions in peri and postoperative settings in general surgery concluded that music intervention had positive effects on reducing patients' anxiety and pain $[6,7]$. Combining pharmacologic and nonpharmacologic methods on anxiety and pain control could probably have a synergistic effect to improve pain relief for the patient. However, we know little about nonpharmacologic approaches to anxiety and pain after maxillofacial surgery. It could be an inexpensive method to reduce pain and anxiety. The main objective of this study is to describe the effects of music intervention on anxiety and pain reduction in maxillofacial and ORL surgery for outpatients. 


\section{PATIENTS AND METHODS}

This study was a descriptive study with a quantitative approach to information. This study was conducted between December 2015 and April 2016 in the department of ORL and maxillofacial surgery of Poissy/Saint-Germain-en-Laye hospital at Saint-Germain-en-Laye (France). Participants were enrolled in the study if they fulfilled the following criteria: aged > 16 years, agree to participate in the study and to answer to a questionnaire, alert and oriented regarding person, place, time, and situation, having tooth extraction surgery which was the most frequent surgery for outpatients in our hospital. Exclusion criteria for patients were: non french-speaker, mental retardation, dementia, bilateral anacousia, psychiatric disorders, and the inability to see sufficiently to mark the visual analog scale (VAS). Informed consent of all patients was obtained before treatment.

The music intervention consisted of listening with headphones to an MP3 easy-listening and relaxing music for at least fifteen minutes in the waiting hall of the operation theatre before the first ambulation. The music had $50-80$ beats per minute or less, to decrease the chance of increasing anxiety. MP3 easy-listening music is shown in Table 1. A 8-questions questionnaire (Figure 1) was constructed to obtain relevant information from participants about their opinion regarding listening to music before surgery. The questionnaire was including a scale pain and anxiety. Patients who listened to music had to answer to the questionnaire one hour after the surgery in the ambulatory department. Patients who didn't listen to music were asked to give the measure of their pain after surgery and the measure of their anxiety before and after surgery. Demographic and anesthesiologic data as specified in Table 2 were also collected. None of the patients had anxiolytics medication before general anesthesia and surgery. None of the patients had local anesthesia. For patients who underwent tooth extractions, general anesthesia and surgical duration were similar. The measures used in this study included a Visual Analog Scale (VAS) for pain, and a VAS for anxiety. The VAS is used to measure various subjective clinical phenomena, including pain and anxiety. The VAS consists of a $10-\mathrm{cm}$ horizontal line with right angles at each end with 
word anchors depicting extremes in the phenomenon being measured. Patients mark on the line exactly where they perceive the phenomenon to fall on the continuum. A ruler is used to measure from the far left of the scale to the subject's mark, and the score is reported as the length measured in millimeters. The VAS is quick, easy to use, and easy to score, and it provides a method to compare the findings to previous results. The VAS also provides ratiolevel data, allowing more robust parametric statistical analysis. When used to assess pain, the far left anchor indicated "no pain", and the far right anchor indicated "pain as bad as it could possibly be". The VAS pain is commonly use in surgery. Concurrent validity of the VAS to measure the self-report of anxiety has been demonstrated when scores were compared with Spielberger's (1983) State Anxiety Inventory [8].

The primary endpoint was to determine patients' opinion regarding listening to music before maxillofacial surgery: whether or not helping to decrease anxiety before surgery (question 7 of the questionnaire, figure 1). Secondary endpoints were to determine the VAS pain mean after surgery in patient who Accepted to Listen to Music (ALM), the VAS anxiety mean before surgery in patients who ALM, the VAS anxiety mean after surgery in patients who ALM and to determine if patients wanted to listen to their own playlist.

In addition, we decided to compare VAS anxiety and pain mean between patients who Accepted to Listen to Music (ALM) and who Refused to Listen to Music (RLM). Tooth extraction surgery patients were chosen because there were few biases in this group: same surgeon, same surgery, same procedure, many patients. P values for the analysis of the secondary endpoints were obtained using the test of Wilcoxon signed rank, with $p<0.05$ considered statistically significant. 


\section{RESULTS}

A total of 19 patients accepted to listen to music and 8 patients refused to listen to music (Figure 2). Analysis of the patients characteristics (Table 2) showed that the average (standard deviation) age was $25,5 \pm 4,8$ years. The sex ratio was $1: 1$. No significant differences were found between the ALM patients and the RLM patients regarding any of the demographic characteristics, including gender, age, and ethnicity. Concerning the primary endpoint, $78,9 \%$ of the patients considered that listening to music before surgery have decreased their anxiety (Table 3). Among the patients that considered that listening to music before surgery have decreased their anxiety, $31,5 \%$ of them said music is helpful before surgery, partially helpful for $58 \%$ of them, needless for $10,5 \%$ of them (Table 4 ). The mean (Standard Deviation, SD) of VAS pain of patients who ALM after surgery was $3,42(1,95)$, the mean (SD) of VAS anxiety of patients who ALM before surgery was $3,1(2,3)$, the mean (SD) of VAS anxiety after surgery in patients who ALM was $1,21(0,85)$ (Table 5). There was a statistically significantly difference of the VAS anxiety mean (SD) before surgery between patients who $\operatorname{ALM} 3,10(2,30)$ and who $\operatorname{RLM} 6,12(1,88)(p=0,005)$. There was a statistically significantly difference of the VAS anxiety mean (SD) after surgery between patients who $\operatorname{ALM} 1,21(0,85)$ and who RLM 2,62 (1,30) $(p=0,009)$ (Table 6$) .50 \%$ of the patients wanted to choose their own music. 


\section{DISCUSSION}

In this study, music therapy before an ambulatory maxillofacial surgery appears to have a synergistic effect with anesthesia to improve anxiety relief for the patient. $78,9 \%$ of the patients considered that listening to music before surgery decreased their anxiety. We noted a statistically significantly difference of the VAS anxiety mean (SD) before and after surgery between patients who ALM and who RLM.

Most of the studies on music therapy in surgery concern digestive and gynecologic surgery [9]. To our knowledge, there are few studies on music therapy before maxillofacial or ORL surgery [10]. This study is the first that study the effects of music intervention on anxiety and pain reduction in maxillofacial and ORL surgery. Many studies have evaluated the effects of music on sedative use, neurohormonal responses, heart rate, blood pressure, respiratory rate $[11,12]$. These criteria are signals of stress and anxiety. We studied the VAS pain and the VAS anxiety that are hard criteria.

A limitation of this study is the lack of a control group and the small number of patients. We didn't propose to our patients to listen to their own music to reduce bias. Most of the studies have included around two to three hundred patients but these studies were multicentred and were studying effect of music on patients undergoing gynecologic surgery. Despite the low number of patients enrolled, our values of pain after surgery in patients who ALM were consistent with those obtained in other studies $[13,14]$. Our results should be taken carefully into account because this study is a descriptive study with low-level evidence. However, our results of VAS anxiety mean and VAS pain in patients who listened to music before undergoing tooth extraction can be a helpful basis for statistical considerations if a randomized controlled study is conduct in maxillofacial surgery.

In this study, $78,9 \%$ of the patients felt that listening to music before surgery decreased their anxiety. Among the patients that felt that listening to music before surgery decreased their anxiety, $10,5 \%$ of them said music is not helpful probably because these patients had a low 
anxiety. Easy-listening music was offered because music with relaxing melody and pleasant rhythms has been shown to produce a calming effect and to decrease anxiety [15].

Regarding the pathophysiology, the chronology of events in acute stress is as follows. In response to a perceived event, catecholaminergic transmissions and $\mathrm{CRH}$ (Corticotropin Releasing Factor produced by the hypothalamus) are activated in less than seconds, followed by ACTH (AdrenoCorticoTrophic Hormone produced by the pituitary gland) and other pituitary hormones including glucagon. Gonadotropins are inhibited. Several minutes' later corticosteroids are released by the cortex of the adrenal gland. The hypothalamus tract project to the brainstem structures and the release of $\mathrm{CRH}$ is activating the sympathetic system. Thus, the adrenal medulla is stimulated and release adrenaline into the blood circulation. The physiological stressor increases cardiovascular rythm, immune system, mobilization of energy sources. It reduces sexual and reproductive potential, appetite and increases cerebral blood flow, and the initiation of the memory consolidation process (central action on the hippocampus). Music therapy seems to decrease stress by a negative feedback on production of $\mathrm{CRH}[16,17]$.

In conclusion, music seems to be an easy and inexpensive approach to help patients to reduce anxiety before surgery. An interventional controlled and randomized study is needed to demonstrate the positive impact of music on anxiety before maxillofacial surgery. 


\section{ACKNOWLEDGMENTS}

D.DJELAILIA., JP. GRANIER, E. ROBBEN, H. KEILANI., S. COCCOLO, M. LOURENCO, MF. MALAISE, E. MENDES, M. SUHAS, A. TENCE.

Declaration of interests

The authors declare that they have no conflicts of interest related to this article.

Role of the funding source: there are no financial sources reported

Ethical issues: informed consent was required.

Ethic board approval was obtained.

Informed consent: Informed consent was obtained

REFERENCES 
[1] Atkinson HC, Currie J, Moodie J, Carson S, Evans S, Worthington JP, Steenberg LJ, Bisley E, Frampton C. Combination paracetamol and ibuprofen for pain relief after oral surgery: a dose ranging study. Eur J Clin Pharmacol. 2015 May;71(5):579-87.

[2] Van der Bijl P, Roelofse JA, Joubert JJ, van Zyl JF. Comparison of various physiologic and psychomotor parameters in patients sedated with intravenous lorazepam, diazepam, or midazolam during oral surgery. J Oral Maxillofac Surg. 1991 Jul;49(7):672-8; discussion 6789.

[3] Bechtold ML, Perez RA, Puli SR, Marshall JB. Effect of music on patients undergoing outpatient colonoscopy. World J Gastroenterol 2006;12:7309-12

[4] Koelsch S, Fuermetz J, Sack U, Bauer K, Hohenadel M, Wiegel M, Kaisers UX, Heinke W.. Effects of Music Listening on Cortisol Levels and Propofol Consumption during Spinal Anesthesia. Front Psychol. 2011 Apr 5;2:58.

[5] Wu J, Chaplin W, Amico J, Butler M, Ojie MJ, Hennedy D, Clemow L. Music for surgical abortion care study: a randomized controlled pilot study. Contraception. 2012 May;85(5):496502.

[6] Nilsson U. The anxiety- and pain-reducing effects of music interventions: a systematic review. AORN J. 2008 Apr;87(4):780-807.

[7] Hole J et al. Music as an aid for postoperative recovery in adults:

a systematic review and meta-analysis. Lancet. 2015 Oct 24;386(10004):1659-71.

[8] Elliot, D. Comparison of three instruments for measuring patient anxiety in a coronary care unit. Intensive Critical Care Nurse, 1993, 9, 195-200.

[9] Sin WM, Chow KM. Effect of Music Therapy on Postoperative Pain Management in Gynecological Patients: A Literature Review. Pain Manag Nurs. 2015 Dec;16(6):978-87. 
[10] Gómez-Urquiza JL, Hueso-Montoro C, Urquiza-Olmo J, Ibarrondo-Crespo R, GonzálezJiménez E, Schmidt-Riovalle J. A randomized controlled trial of the effect of a photographic display with and without music on pre-operative anxiety. J Adv Nurs. 2016 Feb 16.

[11] Leardi S, Pietroletti R, Angeloni G, Necozione S, Ranalletta G, Del Gusto B. Randomized clinical trial examining the effect of music therapy in stress response to day surgery. Br J Surg 2007;94:943-7.

[12] Nilsson U, Unosson M, Rawal N. Stress reduction and analgesia in patients exposed to calming music postoperatively: a randomized controlled trial. Eur J Anaesthesiol 2005;22:96102.

[13] Yao J, Lee KK, McGrath C, Wu YN, Li KY, Mattheos N. Comparison of patient centered outcomes after routine implant placement, teeth extraction, and periodontalsurgical procedures. Clin Oral Implants Res. 2016 Mar 11.

[14] Kim YK, Kim SM, Myoung H. Musical intervention reduces patients' anxiety in surgical extraction of an impacted mandibular third molar. J Oral Maxillofac Surg. 2011 Apr;69(4):1036-45.

[15] MacClelland, D. C. Therapeutic communication through music. Point of View, 1982, 19, $4-5$.

[16] Smagin GN, Heinrichs SC, Dunn AJ. The role of CRH in behavioral responses to stress. Peptides. 2001 May;22(5):713-24.

[17] Özer N, Karaman Özlü Z, Arslan S, Günes N. Effect of music on postoperative pain and physiologic parameters of patients after open heart surgery. Pain Manag Nurs. 2013 Mar;14(1):20-8. 
Tables:

Table 1. MP3 easy-listening music

Table 2. Characteristics of the study population

Table 3. Primary outcome: patients' opinions regarding listening to music before maxillofacial or ORL surgery: whether or not helping to decrease anxiety before surgery.

Table 4. Patients opinions regarding listening to music before maxillofacial or ORL surgery

Table 5. Secondary outcomes: VAS pain mean and VAS anxiety in patients who ALM

Table 6. Secondary outcomes: VAS pain mean and VAS anxiety mean comparison between the patients who ALM and who RLM 


\section{Figures}

Figure 1. 8-questions questionnaire

Figure 2. Flowchart of the study. 
Tables:

Table 1.

\begin{tabular}{|c|c|}
\hline Label & Origins - 000273, Silent Music \\
\hline Series & $\begin{array}{c}\text { Collection Oxygène - Magie de la musique } \\
\text { et du son naturel }\end{array}$ \\
\hline Format & CD, compilation \\
\hline Country & France \\
\hline Date & Electronic \\
\hline Type & New Age, Field Recording \\
\hline Style &
\end{tabular}

Table 2.

\begin{tabular}{|c|c|c|}
\hline Characteristics & ALM patients $(\mathrm{n}=19)$ & RLM patients $(\mathrm{n}=8)$ \\
\hline Gender $\mathrm{n}(\%)$ & 47,3 & 50 \\
\hline Male & 52,7 & $35 \pm 18,8^{\circ}$ \\
\hline Female & $25,5 \pm 4,8^{\circ}$ & \\
\hline Age, years, mean (SD) & & 72 \\
\hline Ethnicity n (\%) & 75 & 28 \\
\hline European & 20 & 0 \\
\hline Africaan & 5 & 100 \\
\hline Asian & 100 & 0 \\
\hline Anesthesia $\mathrm{n}(\%)$ & 0 & \\
\hline General & & \\
\hline Local & & \\
\hline
\end{tabular}

SD: Standard Deviation

-The more or less correspond to mean values +/- standard deviation 
Table 3.

\begin{tabular}{|l|l|}
\hline & ALM patients $(\mathrm{n}=19)$ \\
\hline Decreasing anxiety (\%) & 78,9 \\
\hline Not decreasing anxiety (\%) & 21,1 \\
\hline
\end{tabular}

Table 4.

\begin{tabular}{|l|l|}
\hline & ALM patients $(\mathrm{n}=19)$ \\
\hline Helpful (\%) & 31,5 \\
\hline Partially helpful (\%) & 58 \\
\hline Not helpful (\%) & 10,5 \\
\hline
\end{tabular}

Table 5.

\begin{tabular}{|c|c|}
\hline & $\begin{array}{c}\text { ALM patients } \\
(\mathrm{n}=19)\end{array}$ \\
\hline $\begin{array}{c}\text { VAS pain after } \\
\text { surgery }\end{array}$ & $3,42 \pm 1,95^{\circ}$ \\
\hline $\begin{array}{c}\text { VAS anxiety before } \\
\text { surgery }\end{array}$ & $3,1 \pm 2,3^{\circ}$ \\
\hline $\begin{array}{c}\text { VAS anxiety after } \\
\text { surgery }\end{array}$ & $1,21 \pm 0,85^{\circ}$ \\
\hline
\end{tabular}

${ }^{\circ}$ The more or less correspond to mean values $+/$ - standard deviation 
Table 6.

\begin{tabular}{|c|c|c|c|}
\hline & ALM patients $(n=19)$ & RLM patients $(n=8)$ & $p$ values \\
\hline VAS pain after surgery & $3,42 \pm 1,95^{\circ}$ & $4,50 \pm 2,07^{\circ}$ & $p=0,30$ \\
\hline VAS anxiety before surgery & $3,1 \pm 2,3^{\circ}$ & $6,12 \pm 1,88^{\circ}$ & $p=0,005^{*}$ \\
\hline VAS anxiety after surgery & $1,21 \pm 0,85^{\circ}$ & $2,62 \pm 1,30^{\circ}$ & $p=0,009^{*}$ \\
\hline
\end{tabular}

- The more or less correspond to mean values +/- standard deviation

* Statistically significant result $p<0.05$ 
1. Please mark on the line the number that corresponds to the intensity of your pain after surgery

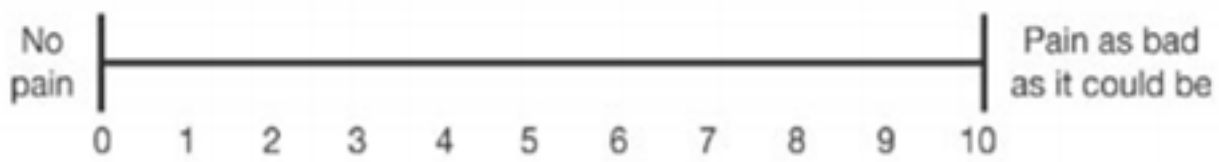

2. Please mark on the line the number that corresponds to the intensity of your anxiety before surgery after listening to music

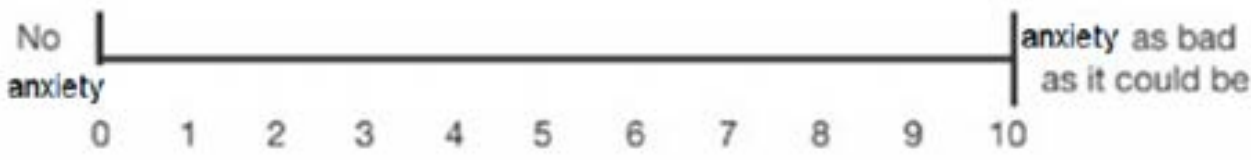

3. Please mark on the line the number that corresponds to the intensity of your anxiety after surgery

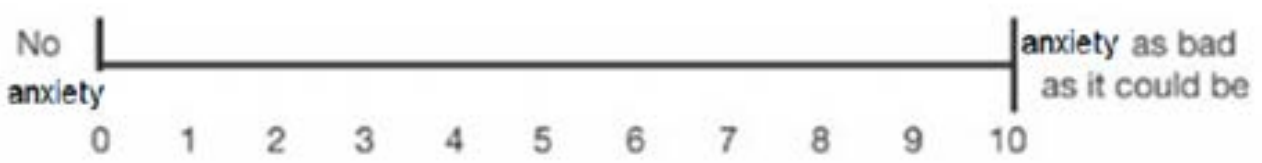

4. In your opinion, how would you characterize listening to music to relieve anxiety? (check the box)

Helpful

Partially helpful

Not helpful

5. Would you like to listen to music again if you needed another ENT surgery? (check the box) Yes

No

6. Would you like to choose and listen to your own music? (check the box)

Yes

No

7. Do you feel that listening to music decreased your anxiety? (check the box) Yes

No

8. Do you have any comments about this device? (If so, thank you to indicate it below) 
Patients that were offered to listen to music $(n=39)$

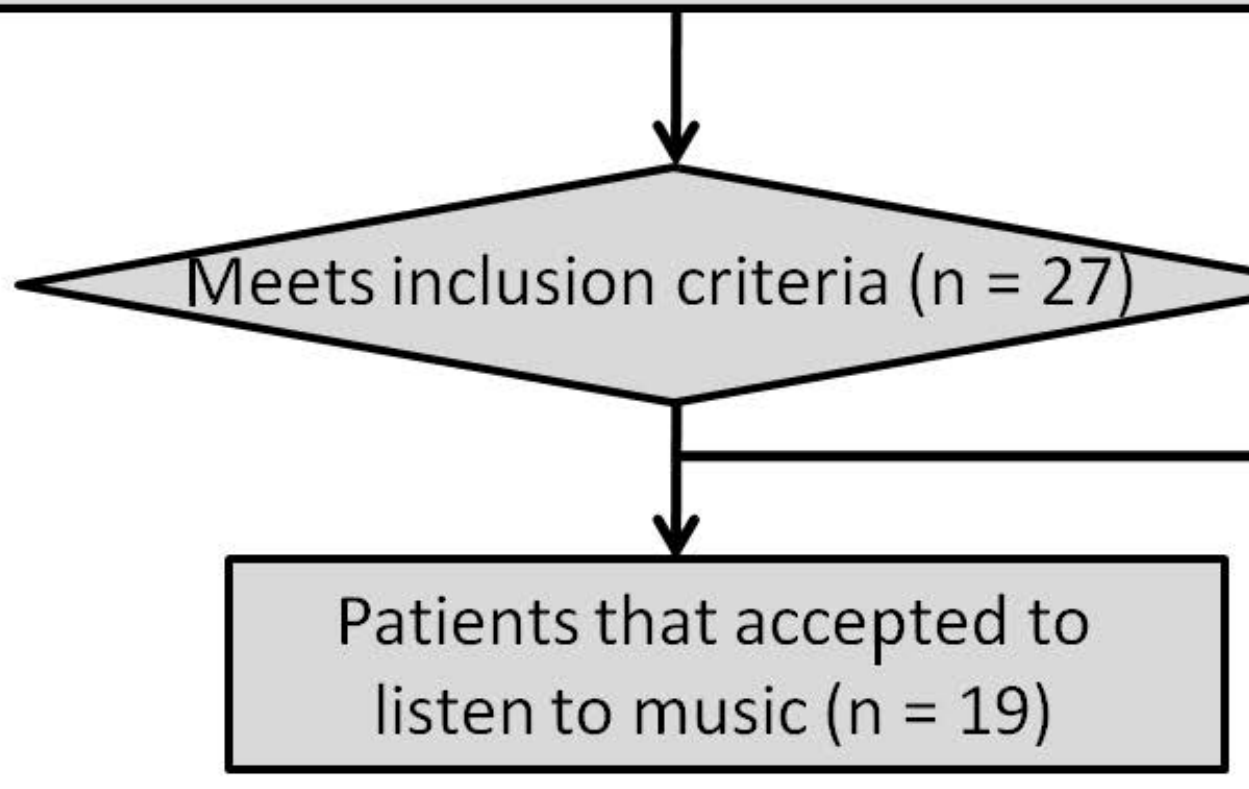

Patients that refused to listen to music $(n=8)$ Lack of interest $(n=4)$ Mistrust $(n=4)$ 